\title{
Salvage of bleeding renal allograft following biopsy, with suture technique: a case report
}

\author{
Aruna Prasanna ${ }^{1}$, Ranga Migara Weerakkody ${ }^{2 *}$, Eranga Sanjeewa Wijewickrama ${ }^{3}$, \\ Mohammed Rezni Nizam Cassim ${ }^{4}$ and Mandika Wijeyarathne ${ }^{4}$
}

\begin{abstract}
Background: Percutaneous renal biopsy is a valuable procedure in the management of and prognostication for patients with renal disease. Complications, although rare, occur with renal biopsies. Arteriovenous fistulas and heavy bleeding are notable complications. In this report, we describe simple suturing of the biopsy tract for salvage of a graft destined for a nephrectomy due to a profusely bleeding arteriovenous fistula.

Case presentation: A 20-year-old Sri Lankan man with end-stage renal disease due to steroid-resistant nephrotic syndrome underwent a renal transplant. He had poor urine output following the surgery, and a renal biopsy was performed to diagnose his renal pathology. He experienced poorly controlled postprocedural hypertension, and he had four episodes of gross hematuria that required blood transfusion. Coil embolization was delayed due to technical issues, and a graft nephrectomy was planned following the fourth episode of hematuria, which was the most severe. A Doppler scan revealed a slender, iatrogenic arteriovenous fistula corresponding to the biopsy tract, with very high flow rates. With knowledge of the anatomy of the fistula, we performed suturing of the tract to obliterate the fistula as a last resort to salvage the graft. The surgical procedure stopped the bleeding, and the patient made a full recovery with an excellent quality of life.

Conclusions: In our patient, a renal transplant biopsy revealed acute tubular necrosis. The incidence and treatment of fistulas and differences in complication rates among native and graft kidney biopsies are discussed.
\end{abstract}

Keywords: Renal biopsy, Arteriovenous fistula, Allograft, Bleeding

\section{Background}

Percutaneous renal biopsy provides crucial evidence in the assessment and management of allograft dysfunction. It is an invasive procedure with complications, and most of them are related to bleeding. Sometimes the complications are severe enough to require a nephrectomy or to result in death. Hematuria, hematoma formation, arteriovenous fistulas (AVFs), pseudoaneurysm, and clot retention are the commonest complications related to bleeding [1-3]. Most of the bleeding episodes respond to conservative management, including bed rest, blood transfusions, and correction of clotting abnormalities.

\footnotetext{
* Correspondence: rangamw2003@yahoo.com

${ }^{2}$ Renal Services, University Medical Unit, National Hospital of Sri Lanka, Regent Street, Colombo 10, Sri Lanka

Full list of author information is available at the end of the article
}

Troublesome bleeding requires active intervention, coil embolization, or nephrectomy. We report a case of a patient in whom suturing of a biopsy tract containing an AVF was used to stop the bleeding and eventually salvage the graft.

\section{Case presentation}

A 20-year-old Sri Lankan man diagnosed with end-stage renal failure associated with childhood steroid-resistant nephrotic syndrome underwent a renal transplant. His altruistic donor had $\mathrm{ABO}$ and human leukocyte antigen compatibility within acceptable limits. The patient was not sensitized and had received massive doses of immunosuppressants, including steroids, cyclosporine, tacrolimus, azathioprine, mycophenolate, and cyclophosphamide. He had severe growth retardation with height $(1.45 \mathrm{~m})$ and 
weight $(26 \mathrm{~kg})$ well below the third percentile, lack of secondary sexual characteristics, and cushingoid features. He had severe hypertension causing end-organ damage, retinopathy, and left ventricular hypertrophy. Control of his blood pressure had been challenging before the transplant.

He received induction immunosuppression keeping with local induction protocol (intravenous basilixumab $20 \mathrm{mg}$, cyclosporine $20 \mathrm{mg} / \mathrm{kg} / \mathrm{day}$, mycophenolate mofetil $25 \mathrm{mg} /$ $\mathrm{kg} /$ day, and intravenous methylprednisolone $1 \mathrm{~g}$ ). His cold and warm ischemia times were 60 and 24 minutes, respectively. Following surgery, he was managed in a highdependency unit for monitoring and support. Standard immunosuppressive therapy was commenced thereafter.

The patient had poor urine output and became anuric $4 \mathrm{~h}$ after the transplant. Ultrasound-guided renal biopsy was carried out by a trainee nephrologist on the second day after the transplant to assess graft failure. Before the patient's biopsy, his hemoglobin level was $117 \mathrm{~g} / \mathrm{L}$, his platelet count was $178,000 / \mu \mathrm{l}$, his creatinine level was $563 \mu \mathrm{mol} / \mathrm{L}$, and his international normalized ratio (INR) was 1.1. We used real-time ultrasound to guide the biopsy and a Bard ${ }^{\circ}$ 18-gauge spring-loaded disposable gun (Bard Biopsy Systems, Tempe, AZ, USA) to collect tissue. With two firings of the gun, we obtained two tissue cores. The patient's blood pressure before the biopsy was $160 / 100 \mathrm{mmHg}$, but postbiopsy it rose to $220 / 120 \mathrm{mmHg}$. Immediately after the procedure, the patient complained of severe suprapubic pain, and gross hematuria with clots was noted. Urgent surgical review was sought, and bladder irrigation was started via a cystostomy. The patient's volume depletion was treated with crystalloids and packed red blood cell transfusions. His blood pressure was controlled with intravenous nitroglycerin and labetalol. Within a couple of hours, we were able to control the patient's bleeding. However, he had three further episodes of bleeding amounting to $500-750 \mathrm{ml}$ per episode, which was massive in relation to his body weight. Twelve units of blood were transfused in total to control his hypovolemia over the course of $60 \mathrm{~h}$. Fortunately, the patient did not develop massive transfusion syndrome. His highest INR was 1.3, his longest activated partial thromboplastin time was 39.4 seconds, and his lowest platelet count was $130,000 / \mu l$. We did not obtain a thromboelastogram before the surgery, and desmopressin was not used preoperatively, in keeping with the local protocol.

A duplex ultrasound scan showed the presence of an iatrogenic, slender AVF $(2-3 \mathrm{~mm}$ in width and $25 \mathrm{~mm}$ long) in close proximity to the biopsy tract (Fig. 1), as well as a small, perinephric hematoma (not shown). The flow of the AVF was as great as $150 \mathrm{ml} /$ minute and resulted in poor diastolic flow in the rest of the kidney. The pulsatile flow and high resistivity index of 1.0 presented a clinical picture similar to that of acute rejection (Fig. 2). We planned to selectively embolize the feeding vessels of the AVF; however, the interventional radiology department of the National Hospital of Sri Lanka was experiencing technical difficulties, and selective embolization was possible only on the following morning. The patient developed another torrential bleed of $1250 \mathrm{ml}$ in the evening on day 2, and an emergency graft nephrectomy appeared to be the only way to stop his bleeding. His skin was opened through the existing surgical incision, and we

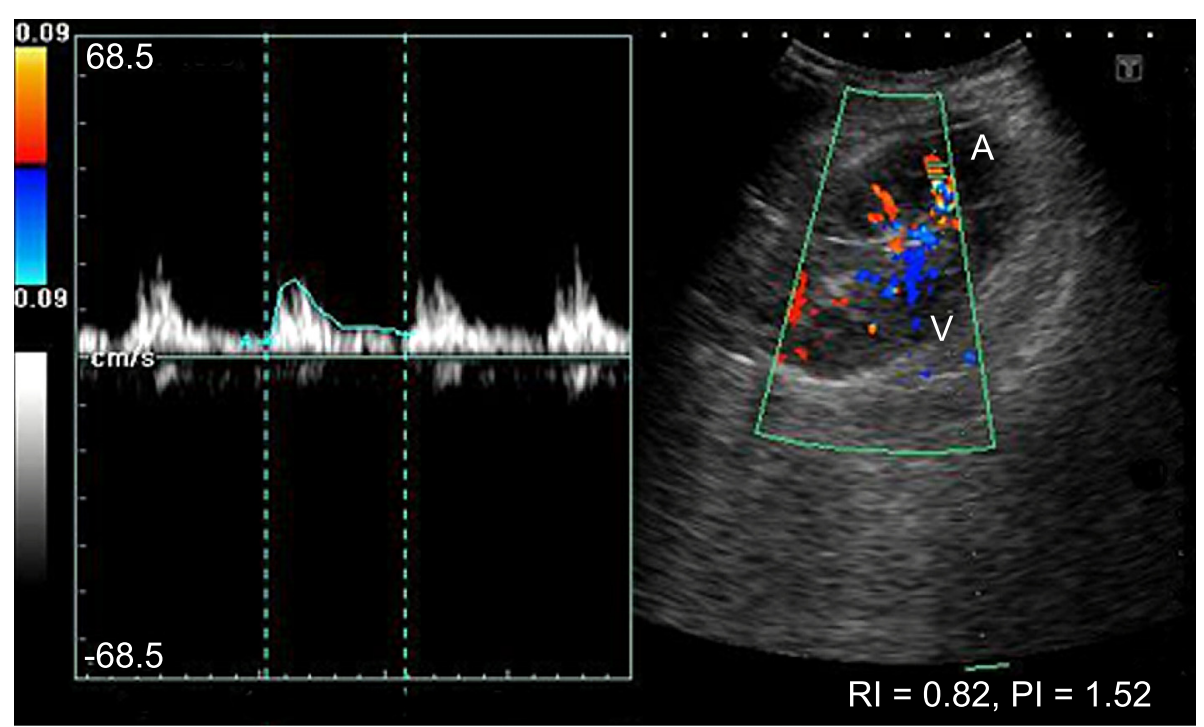

Fig. 1 Doppler sonographic image of the allograft. The superior pole contains a lesion with turbulent flow. The feeding artery (A) and the draining vein $(V$ ) are visible in red and blue, respectively. The lesion shows a mixed arterial and venous flow with a resistivity index of 0.82 . The rest of the kidney showed no diastolic flow, and the resistivity index was 1.0 


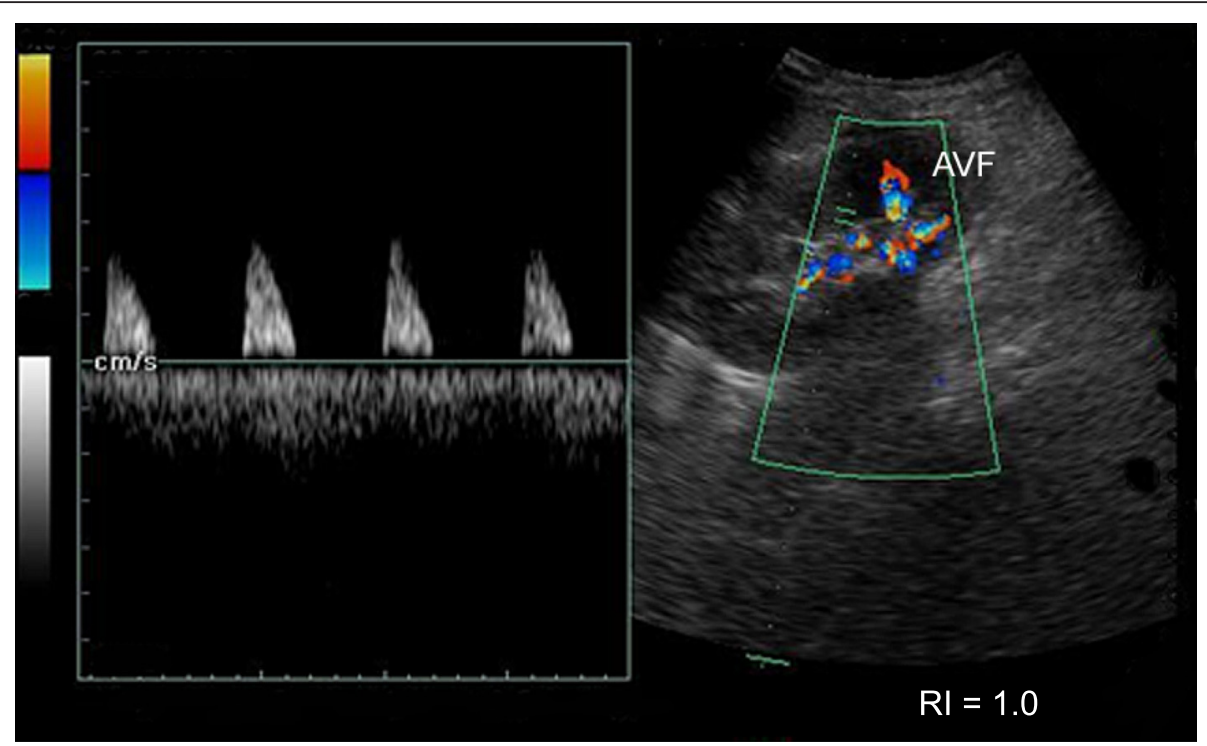

Fig. 2 Doppler sonographic image of the allograft. The flow of the middle pole is assessed in the figure. The arteriovenous fistula (AVF) is visible in the superior pole. Monophasic systolic flow and absent diastolic flow are prominent features, leading to a radiological diagnosis of acute rejection

observed a profusely bleeding biopsy tract (Fig. 3). A minor perinephric hematoma of about $100 \mathrm{ml}$ was observed. The patient's bladder was distended with clots and close to rupture. We were well aware of the anatomy of the AVF, which was slender. We decided to control the bleeding using local pressure (that is, by suturing the tract).

We used a \#0 polyglactin 910 filament to suture the bleeding AVF with an encircling knot cutting through the renal parenchyma. The patient's bleeding resolved, and pulsatile flow in the area surrounding the sutured segment (15\% of the surface area of the kidney) was absent. Suturing was hindered by edema of the surrounding parenchyma, as tight sutures tend to cut through the parenchyma. We evacuated clots via a cystostomy and inserted a suprapubic drain. The patient did not experience any further bleeding. A repeat duplex study showed obliteration of the AVF and change of the flow patterns (from monophasic to biphasic), suggestive of acute tubular necrosis (Fig. 4). A renal biopsy confirmed the radiological diagnosis, and the patient was recommenced on hemodialysis. His urine output improved by day 16 posttransplant, and his creatinine levels reached a baseline of $116 \mu \mathrm{mol} / \mathrm{L}$ by day 20 . He was discharged on day 22 , and at his 18-month follow-up he was doing well, with a creatinine level of $108 \mu \mathrm{mol} / \mathrm{L}$. His height, secondary sexual characteristics, and quality of life had improved. A repeat duplex scan done 6 weeks after the biopsy showed no features of AVF and excellent perfusion of the graft (Figs. 5 and 6).

\section{Discussion}

Renal biopsy is regarded as the gold standard for the diagnosis, prognosis, and management of patients with renal

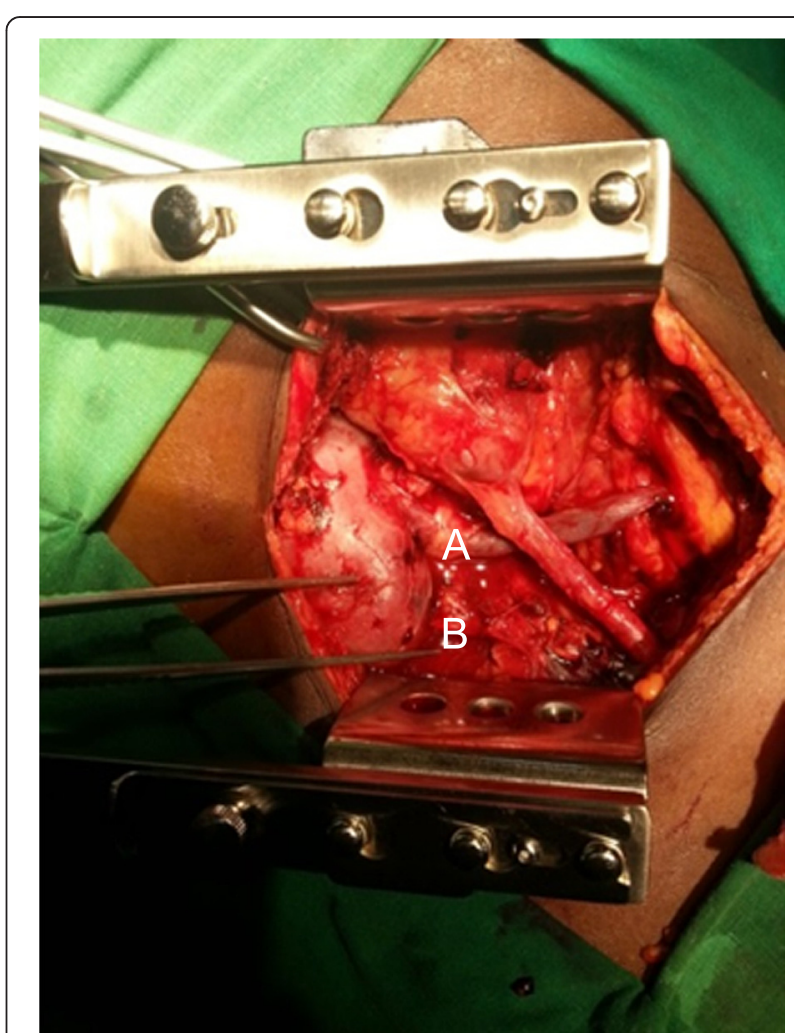

Fig. 3 The surface of the kidney has two biopsy tracts with a common entrance (catch inserted to elaborate) and two separate exits ( $A$ and $B$ ). Tract $A$ was bleeding profusely 


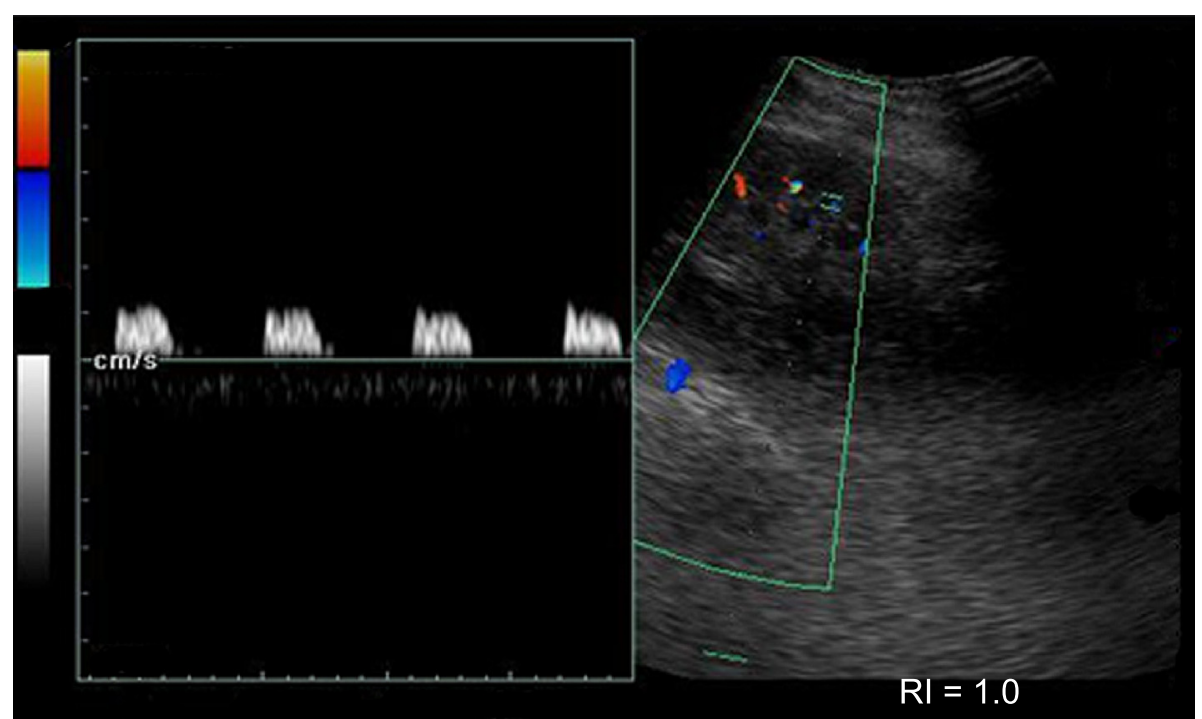

Fig. 4 Doppler sonogram obtained immediately following suturing of the biopsy tract. The flow pattern has changed to biphasic, but diastolic flow is still absent. Note the loss of peripheral circulation on the sonogram. The patient's resistivity index was 1.0, and the radiological diagnosis was consistent with that of acute tubular necrosis

disease. The first renal biopsy dates back more than a century [4]. Advancements in the needle, as well as use of real-time ultrasonography, have gradually improved the technique and the yields of the biopsies [5]. The safety of the procedure has improved considerably, even in the hands of trainee physicians [5, 6]. However, renal biopsy can cause minor to serious complications. Bleeding manifestations include hematuria, hematoma, and profuse bleeding with a consequent need for blood transfusions, coil embolization, or surgical procedures such as nephrectomy; rarely, death can result [3]. Serious complications are rare when risk factors such as hypertension, bleeding, and clotting tests are within acceptable ranges $[7,8]$. Our patient had severe hypertension periprocedurally, which is a well-known risk factor for bleeding. His platelet count and coagulation were within reference ranges. Hypertension is a risk factor for, as well as a consequence of, bleeding. Compression of the kidney by a subcapsular hematoma-commonly following a biopsy-is termed Page kidney, which is a recognized cause of

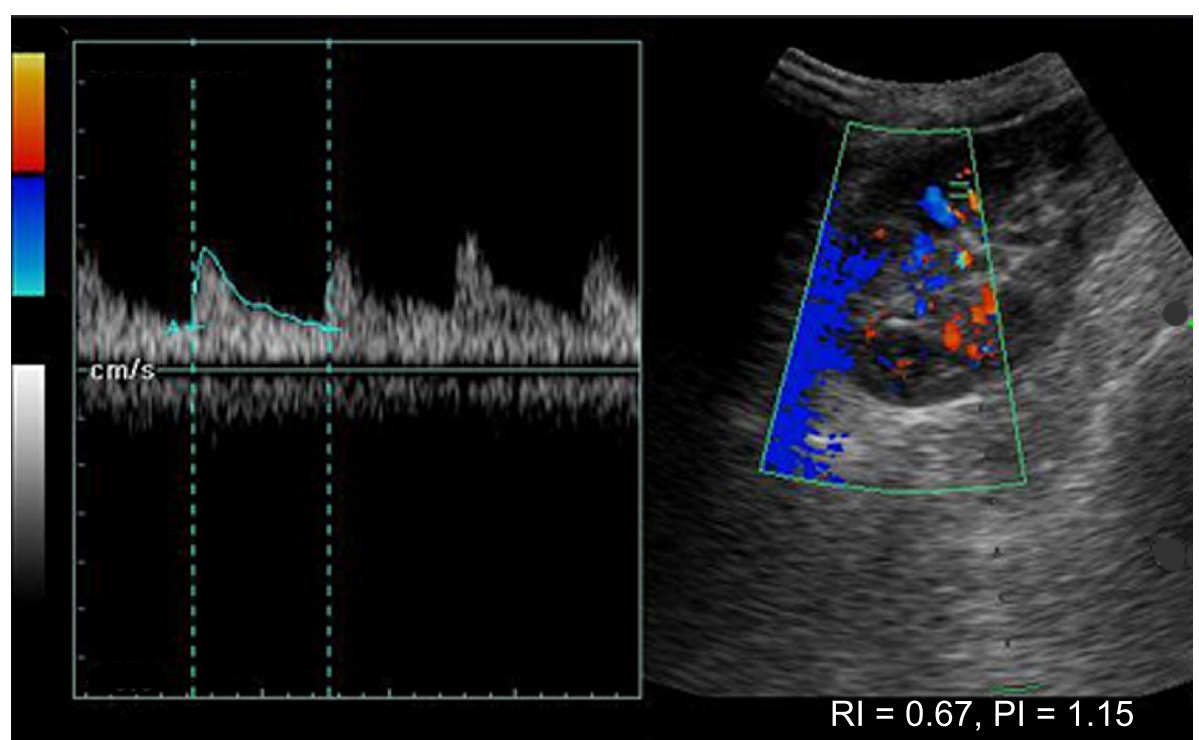

Fig. 5 Doppler sonogram of the allograft 6 weeks later shows flow estimation in the upper pole where the arteriovenous fistula was identified. The scan does not show any turbulent flow or feeding vessels 


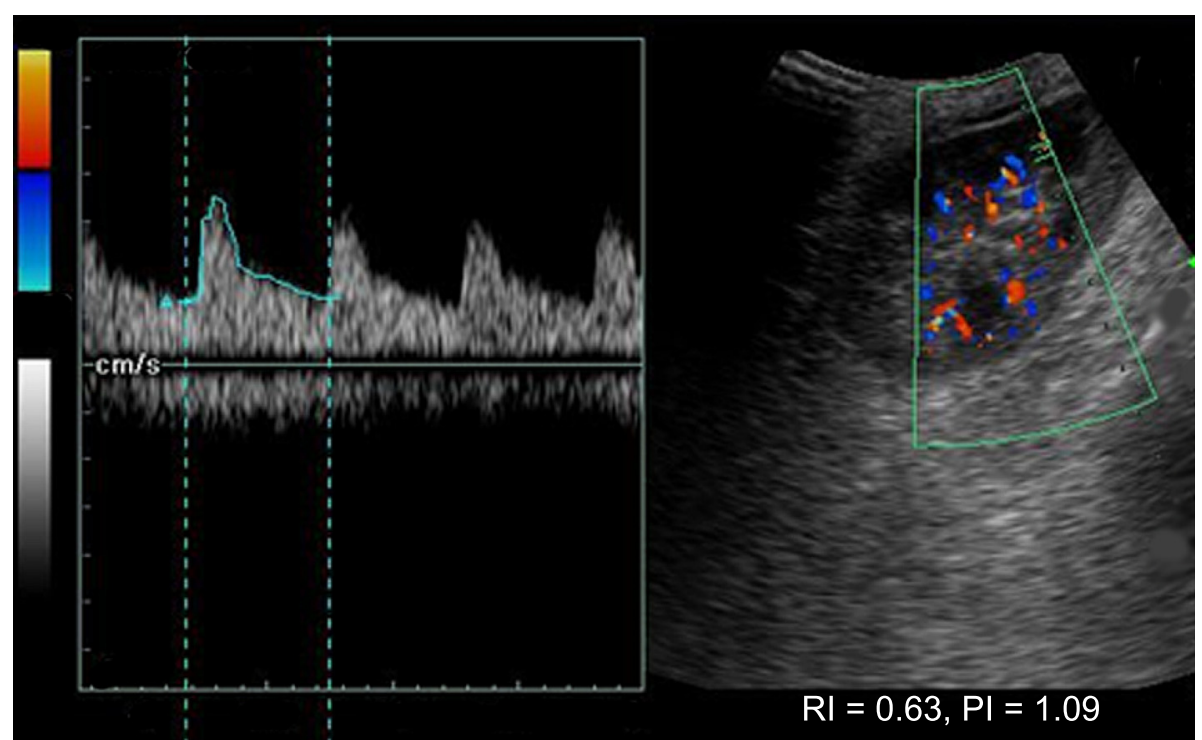

Fig. 6 Doppler sonogram of the allograft 6 weeks later shows flow estimation in the lower pole. The patient's resistivity indices are $0.63-0.67$ and flow patterns are normal, which are features of a normal allograft

secondary hypertension. The acute rise of our patient's blood pressure could have been secondary to a Page allograft kidney. A small perirenal hematoma supports this possibility, though the majority of the bleeding was into the renal pelvis and then into the bladder. Classically, this has been described in native kidneys, but it has been reported in transplanted kidneys as well [9].

Needle biopsies of renal allografts are performed per protocol or for indicated biopsies. Our patient underwent the latter type. The overall reported incidence of bleeding in allograft biopsies varies greatly, ranging from $3 \%$ to $16.5 \%$, and the reported incidence of symptomatic AVFs is about $0.4 \%[3,10,11]$. The complication rates of graft biopsies compared with native biopsies is a subject of debate. Researchers in some studies have reported lower complication rates in graft biopsies $(28.9 \%$ versus $19.5 \%, p=0.033$ ) [12-14], while others have shown twice as many serious complications (hematoma, hemoperitoneum, and AVF) [10]. The management of complications is straightforward. Bed rest itself resolves most of the minor bleeding episodes, and only severe bleeding episodes require blood transfusion, radiological intervention, and nephrectomy.

In native renal biopsies, AVFs occur at rates of 1-18 \% $[15,16]$. Around $39 \%$ of them are symptomatic. The majority (87\%) resolve spontaneously, and only $13 \%$ require treatment [15]. Gross hematuria occurs in less than $10 \%$ of patients with acquired AVF [17]. Our patient had torrential bleeding episodes, and we did not have access to interventional radiology facilities overnight. Coil embolization carries an excellent prognosis and should be regarded as the first line of therapy. The procedure we describe in this report was done as a last resort to salvage the kidney. To the best of our knowledge, this is the first reported case of suturing of a biopsy tract containing an AVF to salvage the graft.

\section{Conclusions}

Exploratory surgery can effectively and promptly control bleeding and correct underlying anatomical problems. All efforts must be made to salvage the viable allograft.

\section{Consent}

Written informed consent was obtained from the patient for publication of this case report and any accompanying images. A copy of the written consent is available for review by the Editor-in-Chief of this journal.

\section{Abbreviations}

AVF: arteriovenous fistula; INR: international normalized ratio.

\section{Competing interests}

The authors declare that they have no competing interests.

\section{Authors' contributions}

WLADAP performed the surgical procedure. RMW and ESW provided nephrologic care in the pre- and posttransplant periods. MRNC and SMW performed the initial surgery and provided postoperative care. RMW and WLADAP wrote the manuscript. ESW, MRNC, and SMW critically analyzed the manuscript. All authors read and approved the final manuscript.

\section{Author details}

${ }^{1}$ Vascular and Transplant Division, University Surgical Unit, National Hospital of Sri Lanka, Regent Street, Colombo 10, Sri Lanka. ${ }^{2}$ Renal Services, University Medical Unit, National Hospital of Sri Lanka, Regent Street, Colombo 10, Sri Lanka. ${ }^{3}$ Department of Clinical Medicine, Faculty of Medicine, University of Colombo, Kynsey Road, Colombo 8, Sri Lanka. ${ }^{4}$ Vascular and Transplant Division, Department of Surgery, Faculty of Medicine, University of Colombo, Kynsey Road, Colombo 8, Sri Lanka. 
Received: 8 January 2016 Accepted: 15 March 2016

\section{Published online: 02 April 2016}

\section{References}

1. Diaz-Buxo JA, Donadio Jr JV. Complications and percutaneous renal biopsy: an analysis of 1000 consecutive biopsies. Clin Nephrol. 1975;4:223-7.

2. Karafin L, Kendall AR, Fleisher DS. Urologic complications in percutaneous renal biopsy in children. J Urol. 1970;103:332-5.

3. Whittier WL, Korbet SM. Timing of complications in percutaneous renal biopsy. J Am Soc Nephrol. 2004;15:142-7.

4. Cameron JS, Hicks J. The introduction of renal biopsy into nephrology from 1901 to 1961: a paradigm of the forming of nephrology by technology. Am J Nephrol. 1997;17:347-58.

5. Prasad N, Kumar S, Manjunath R, Bhadauria D, Kaul A, Sharma RK, et al. Real-time ultrasound-guided percutaneous renal biopsy with needle guide by nephrologists decreases post-biopsy complications. Clin Kidney J. 2015;8(2):151-6.

6. Fülöp T, Alemu B, Dossabhoy NR, Bain JH, Pruett DE, Szombathelyi A, et al. Safety and efficacy of percutaneous renal biopsy by physicians-in-training in an academic teaching setting. South Med J. 2014;107(8):520-5.

7. Kersnik Levart T, Kenig A, Buturović Ponikvar J, Ferluga D, Avgustin Cavić M, Kenda RB. Real-time ultrasound-guided renal biopsy with a biopsy gun in children: safety and efficacy. Acta Paediatr. 2001;90:1394-7.

8. Mendelssohn DC, Cole EH. Outcomes of percutaneous kidney biopsy, including those of solitary native kidneys. Am J Kidney Dis. 1995;26:580-5.

9. Gandhi V, Khosravi M, Burns A. Page kidney in a 17-year-old renal allograft BMJ Case Rep. 2012;2012:bcr2012007653. doi:10.1136/bcr-2012-007653.

10. Gainza FJ, Minguela I, Lopez-Vidaur I, Ruiz LM, Lampreabe I. Evaluation of complications due to percutaneous renal biopsy in allografts and native kidneys with color-coded Doppler sonography. Clin Nephrol. 1995;43(5):303-8.

11. Yablon Z, Recupero P, McKenna J, Vella J, Parker MG. Kidney allograft biopsy: timing to complications. Clin Nephrol. 2010;74(1):39-45.

12. Riehl J, Maigatter S, Kierdorf H, Schmitt H, Maurin N, Sieberth HG. Percutaneous renal biopsy: comparison of manual and automated puncture techniques with native and transplanted kidneys. Nephrol Dial Transplant. 1994;9(11):1568-74.

13. Cozens NJ, Murchison JT, Allan PL, Winney RJ. Conventional 15 G needle technique for renal biopsy compared with ultrasound-guided spring-loaded 18 G needle biopsy. Br J Radiol. 1992;65:594-7.

14. Parrish AE. Complications of percutaneous renal biopsy: a review of 37 years' experience. Clin Nephrol. 1992;38:135-41.

15. Tarif N, Dunne PM, Parachuru PR, Bakir AA. Life-threatening hematuria from an arteriovenous fistula complicating an open renal biopsy. Nephron. 1998; 80:66-70.

16. Ullian ME, Molitoris BA. Bilateral congenital renal arteriovenous fistulas. Clin Nephrol. 1987;27:293-7. A published erratum appears in Clin Nephrol. 1987; 28(4):210.

17. Takaha M, Matsumoto A, Ochi K, Takeuchi M, Takemoto M, Sonoda T. Intrarenal arteriovenous malformation. J Urol. 1980;124:315-8.

\section{Submit your next manuscript to BioMed Central and we will help you at every step:}

- We accept pre-submission inquiries

- Our selector tool helps you to find the most relevant journal

- We provide round the clock customer support

- Convenient online submission

- Thorough peer review

- Inclusion in PubMed and all major indexing services

- Maximum visibility for your research

Submit your manuscript at www.biomedcentral.com/submit
Biomed Central 